\section{Sobre los mapas litológicos de las parroquias de la Diócesis de Vitoria-Gasteiz}

LUIS M. MARTínEZ-TORRES

Departamento de Geodinámica

Universidad del País Vasco/Euskal Herriko Unibertsitatea

\section{Resumen}

Del análisis de las litologías empleadas en la construcción de 487 parroquias de la diócesis de Vitoria-Gasteiz, de sus características ornamentales, procedencia y distribución, se deducen varios aspectos a considerar en el análisis histórico y la restauración. En mampostería siempre se utilizan rocas locales. Sin embargo, en sillería y escultura se deduce una evolución temporal. Más concretamente, las litologías más empleadas a lo largo del tiempo según tipologías, han sido: primero las lumaquelas daniense-montienses «tipo Ajarte», después las areniscas albienses tipo «Sierra Elguea» y, por último, las areniscas miocenas «tipo San Formerio». Muy sucintamente, otras de las conclusiones obtenidas han sido: prevalece el gusto del cantero o la tendencia del momento frente a las características litológicas; el tamaño de las rocas a labrar está condicionado por la estratificación y diaclasas de la cantera original; el volumen de roca empleado respecto a su transporte da una idea del número de personas empleadas en la construcción; localmente, en el románico cuartangués, el uso de diferentes litologías de marcado contraste cromático denotan la intencionalidad del artista e implica la ausencia original de pinturas o estucados.

Palabras clave: litología, procedencia, extracción, transporte, cromatismo, iglesias, Álava.

\section{Abstract \\ From the analysis of lithologies used in the construction of 487 parishes in the dioceses of Vitoria-Gasteiz and from their ornamental characteristics, origin and distribution, various aspects can be deduced for consideration in historical analysis and restoration. In masonry local rocks are always used. However, in stonework and sculpture a temporal evolution can be deduced. More concretely, the most used lithologies over the years have been firstly «Ajarte» type Danian-Montian lumachelle, then «Sierra Elguea» type Albian sandstone, and lastly «San Formerio» type Miocene sandstone. Very briefly, other conclusions include that: the stonemason's taste and trends of the moment prevail over lithological characteristics; the size of the rocks to be worked is conditioned by the stratification and joints of the original quarry; the volume of rock used in relation to its transportation gives an idea of the number of people employed in construction; locally, in Romanesque Cuartango, the use of different lithologies with marked chromatic contrast denotes the intention of the artist and implies the original absence of paint or stucco work.}

Key words: lithology, origin, extraction, transportation, chromaticism, churches, Álava.

\section{INTRODUCCIÓN}

Durante el bienio 2000-2001 se realizó un intenso trabajo de campo para el Servicio de Patrimonio Histórico de la Diputación Foral de Álava, gracias al cual se completaron los mapas litológicos de 487 parroquias de la diócesis de Vitoria-Gasteiz.

En las cartografías de las iglesias consideradas se indica el tipo de roca empleado en su construcción y el piso estratigráfico de procedencia. Tanto para el análisis histórico, artístico, constructivo, o sencillamente con vistas a la restauración, es obvia la necesidad de describir previamente los materiales empleados en el monumento y la cantera de origen. Por otra parte, la litología y su procedencia condicionan todo un proceso interdisciplinar que se iniciaría con la exploración de la roca a extraer, arranque, transporte, labra, colocación y posterior mantenimiento o restauración.

\section{METODOLOGÍA}

Los mapas litológicos están soportados en imágenes digitales, sobre las cuales se han delineado los diferentes tipos de roca observados. De cada iglesia se presentan las fotografías de todas las fachadas, la portada y, si es menester, algún detalle singular. Toda esta información está vinculada a una base de datos convencional, en la cual se incluye el nombre del ayuntamiento, localidad, advocación y coordenadas UTM; leyenda a las litologías; geología del substrato; consideraciones geotécnicas; observaciones bibliográficas y comentarios.

Para la descriptiva litológica se han empleado métodos de análisis petrológico al uso, si bien, una vez reconocidas las principales litologías, y por conocimiento de la geología regional, ha preponderado el reconocimiento de visu. En este sentido, debe indicarse que la experiencia previa, adquirida durante la realización del mapa litológico de la Catedral Vieja de Santa María en Vitoria-Gasteiz, ha sido decisiva, pues en ese monumento se encuentran la mayoría de las litologías reconocidas en el resto de la diócesis.

\section{TIPOLOGÍA Y PROCEDENCIA}

A partir de la litología, contenido paleontológico, facies, etc., se determina el nivel estratigráfico de procedencia de la roca. Si además se dispone de información complementaria, como por ejemplo libros de fábrica, es posible determinar el lugar exacto de extracción de la roca.

Como norma general, en mampostería se emplean rocas locales, es decir, muy cercanas o incluso del propio substrato de la construcción. Por tanto, en la selección de rocas para erigir las mamposterías impera el principio de mínimo transporte. 
Respecto a la roca labrable, esto es, la destinada a sillería y escultura, su distribución geográfica dentro de la diócesis denota que no se atiende a criterios de mínimo esfuerzo en el transporte. En general, se aprecia una evolución temporal lineal de cada litología que es progresivamente sustituida por otra. Si ordenamos cronológicamente las litologías más empleadas según tipologías, muy sucintamente el orden temporal se resume en:

1. lumaquelas daniense-montienses «tipo Ajarte», después

2. areniscas albienses tipo «Sierra Elguea» y, por último,

3. areniscas miocenas «tipo San Formerio».

Cuando en un mismo monumento se reconocen varios de los tipos citados, pueden determinarse las rocas reutilizadas de una construcción previa, siguiendo el criterio temporal precedente. El ejemplo más característico son los canecillos románicos, casi siempre realizados en lumaquelas tipo Ajarte. La presencia de piezas de esa litología dentro de otras diferentes, con independencia del motivo tallado, indica que la pieza ha sido reutilizada.

\section{EXTRACCIÓN}

Además del tipo de rocas empleadas y su procedencia, se han presupuesto algunas técnicas de extracción del material constructivo. Como todas las rocas observadas son sedimentarias, parece obvio que la extracción se realizaría aprovechando los planos de discontinuidad: estratificación y diaclasado. Ya que en las rocas citadas estos planos están muy marcados, el arranque se realizaría con cuñas metálicas o de madera, o simples barras de hierro.

Salvo muy pocas excepciones, la laminación interna de las rocas se colocaba horizontal, de manera que el grosor de los sillares o mampuestos viene predeterminado por la potencia original del estrato y no por las necesidades o gustos del cantero. Las piezas mayores, que puntualmente pueden alcanzar dimensiones ciclópeas, son las areniscas tipo Sierra Elguea. Después las areniscas miocenas y, por último, las lumaquelas tipo Ajarte. Sirva como ejemplo, que estas últimas en general son bastante constantes en dimensiones $y$, de acuerdo con las proporciones determinadas en la Catedral Vieja de Santa María, las medidas del bloque unitario son $35,29 \mathrm{~cm}$ (altura), 85,14 cm (anchura) y $31,15 \mathrm{~cm}$ (fondo). Esto implica, que para una densidad de 1,97 $\mathrm{gr} / \mathrm{cm}^{3}$, su peso medio aproximado es de $185 \mathrm{~kg}$.

\section{TRANSPORTE}

Otras consideraciones desarrolladas en el trabajo, aquí parcialmente resumido, se refieren al transporte. Sirva nuevamente como ejemplo la Catedral Vieja de Vitoria-Gasteiz.
En ella, la mampostería está constituida por 184.055 mampuestos de calcarenitas tipo Olárizu, lo que implica un peso total de $5.437 \mathrm{tm}$. Si aceptamos que el transporte se realizó en carros de 10 quintales ( $460 \mathrm{~kg}$ ), el número total de carretadas fue de 11.820

Estas cifras que pueden parecer faraónicas, sin embargo son congruentes si atendemos al factor tiempo. Conjeturemos sobre el número de jornadas que necesitaría un carretero en cargar en la cantera del monte Olárizu o canteras vecinas (Castillo, Gardelegui, Arechavaleta, Mendiola, Lasarte...) los mampuestos de calcarenita, y descargarlos en la plaza de la catedral. La distancia a recorrer es inferior a los $5 \mathrm{~km}$. Aceptemos que el carretero únicamente realizaba 1 viaje al día, esto es $10 \mathrm{~km}$., y que tan sólo trabajaba 5 días por semana. Para transportar 11.820 carretadas necesitaría 45 años y medio.

Es evidente que necesitaríamos un longevo carretero para transportar todo el material. Otra solución sería estirar la jornada laboral para que recorriera al menos $20 \mathrm{~km}$. por día. Por último, otra alternativa posible, sería emplear más transportistas. Suposiciones aparte, sabemos que la catedral cierra la estructura al cabo de aproximadamente 200 años (A. AZKARATE, com. pers.), y que un solo carretero necesitaría 45 años y medio de vida laboral para concluir el transporte. De todo ello se deduce que el número de transportistas en la construcción de la catedral no fue muy elevado. Creemos que similares conclusiones son aplicables a otros gremios.

\section{DURABILIDAD, LABRABILIDAD Y DISTRIBUCIÓN}

Si atendemos a la durabilidad, o capacidad de no alterarse de las rocas, las más duraderas son la del tipo Sierra Elguea, después tipo Ajarte y, por último, las del tipo San Formerio.

Respecto a la labrabilidad o facilidad que presenta una roca al labrado, la más labrables son las areniscas tipo San Formerio, después las lumaquelas tipo Ajarte y por último, muy alejadas en esta escala, las areniscas tipo Sierra Elguea, que entre otras funciones se empleaban como piedra para afilar la propia herramienta de cantería.

En referencia a su distribución, tampoco se deduce una tendencia o evolución en el tiempo, siendo sin duda las lumaquelas tipo Ajarte las que más han viajado, frente a desplazamientos muy similares de las rocas de los tipos Sierra Elguea y San Formerio.

A partir de estas observaciones, puede intuirse que la evolución en el tiempo de las preferencias de los canteros por un tipo de roca determinado, no están condicionadas por su durabilidad, labrabilidad o distribución. Es decir, no se atiende al envejecimiento prematuro de la roca, ni a la mejora de las herramientas, ni a los medios de transporte. 
En conclusión, la selección de una tipología determinada está condicionada al gusto personal del cantero o quizás a la moda del momento, pero sin depender de los aspectos citados.

\section{OTRAS CONSIDERACIONES}

En relación con el uso y distribución de las rocas en un mismo monumento, dentro de la diócesis destacan las ventanas del románico cuartangués. Con independencia del estilo arquitectónico o los motivos labrados, en todas ellas se alternan en capiteles, fustes y arquivoltas hasta cuatro litologías diferentes (Fig. 1). Por una parte, parece que las rocas a tallar han sido seleccionadas por la misma mano o taller $y$, por otra, es evidente que el artista o artistas buscaban el contraste cromático. Si se deseaba una marcada diferenciación del color, debe admitirse que, en ese periodo y zona, no se estucaran o colorearan esos vanos.

El estudio aquí parcialmente presentado abarca todas las parroquias hasta la aparición del cemento. A partir de ese momento los materiales empleados son variados y las rocas proceden de lugares muy diversos. Por ejemplo, la Catedral Nueva de la Inmaculada en Vitoria-Gasteiz se construye con areniscas de Pitillas, en el sur de Navarra. O bien otros dos ejemplos en Vitoria-Gasteiz, que no tienen relación con las parroquias, pero son muy ilustrativos: la Plaza de los Fueros construida con granito rosa de Porriño (Pontevedra) o el pavimento de la calle Dato que procede de la República Popular China. Por tanto, en épocas recientes parecen prevalecer otros criterios económicos o funcionales, sin que pueda deducirse una litología o litologías predominantes.

A modo de conclusión, de las líneas precedentes se deduce que la descripción de las rocas empleadas en construcción y su procedencia, aporta aspectos a considerar en la arqueología de la arquitectura y, en cualquier caso, es necesaria en la restauración o restitución del material pétreo que soportan los monumentos.
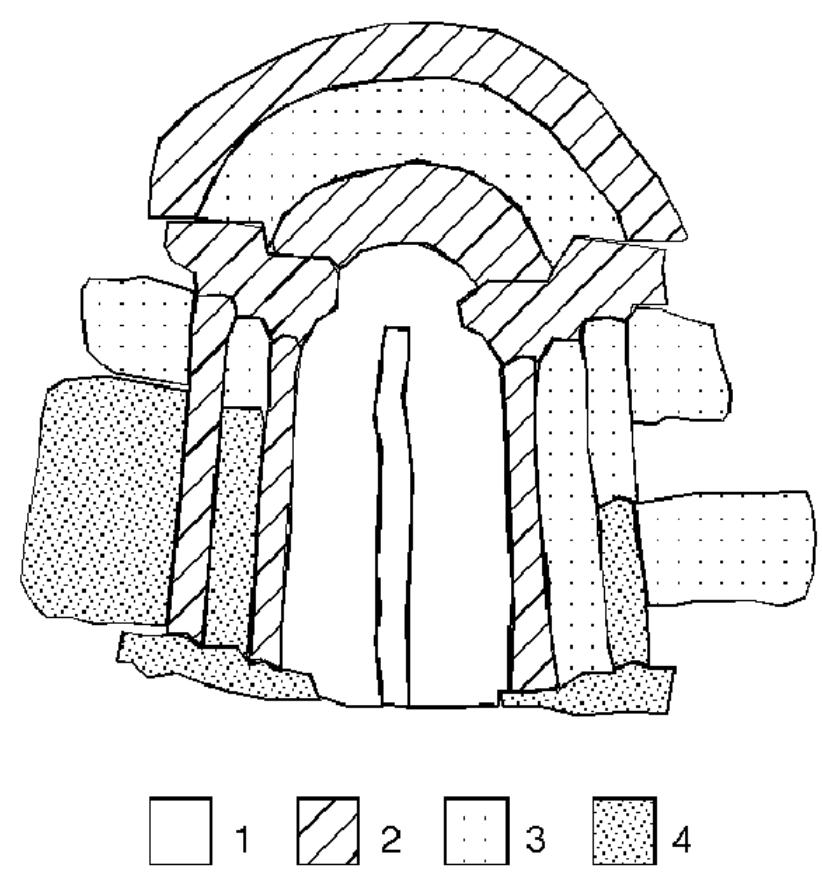

Fig. 1. Ventana del ábside de la iglesia de Ullíbarri de Cuartango (Álava). 1: calizas y calizas margosas locales del Cretácico superior en mampostería y cerrando la ventana; 2: lumaquelas daniense-montienses tipo Ajarte; 3: calcita (¿quizás aragonito?), procedente de alguna grieta o de depósitos endokársticos; 4: areniscas miocenas tipo San Formerio. Debe indicarse que la calcita, numerada con 3 , no es una roca sino un mineral, muy fácil de pulir. La superficies pulidas ofrecen una estructura interna laminada y un intenso color ámbar de fuerte impacto visual. De la distribución de las tipologías rocosas se deduce que el sillar inferior izquierdo de 4 y la columna exterior derecha de 3 y 4 son reposiciones. 